\title{
Catalytic Asymmetric Formal Total Synthesis of (-)-Triptophenolide and (+)-Triptolide
}

\author{
Wen-Dan Xu $\cdot$ Liang-Qun Li $\cdot$ Ming-Ming Li $\cdot$ \\ Hui-Chun Geng $\cdot$ Hong-Bo Qin
}

Received: 13 March 2016/Accepted: 11 April 2016/Published online: 20 April 2016

(C) The Author(s) 2016. This article is published with open access at Springerlink.com

\begin{abstract}
Catalytic asymmetric formal synthesis of (-)-Triptophenolide and (+)-Triptolide have been achieved. Key reaction involves Palladium catalyzed asymmetric conjugate addition of aryl boronic acid to 3-methyl cyclohexe-1-none to form quaternary carbon. Claisen rearrangement and subsequent aldol reaction furnished trans-decaline key intermediate, which assured a formal total synthesis of (-)-Triptophenolide and (+)-Triptolide.
\end{abstract}

Graphical Abstract<smiles>CCOC(=O)C1(C(=O)OCc2ccccc2)CC(=O)C[C@H](c2ccc(C(C)C)c(OCc3ccccc3)c2)C1</smiles>

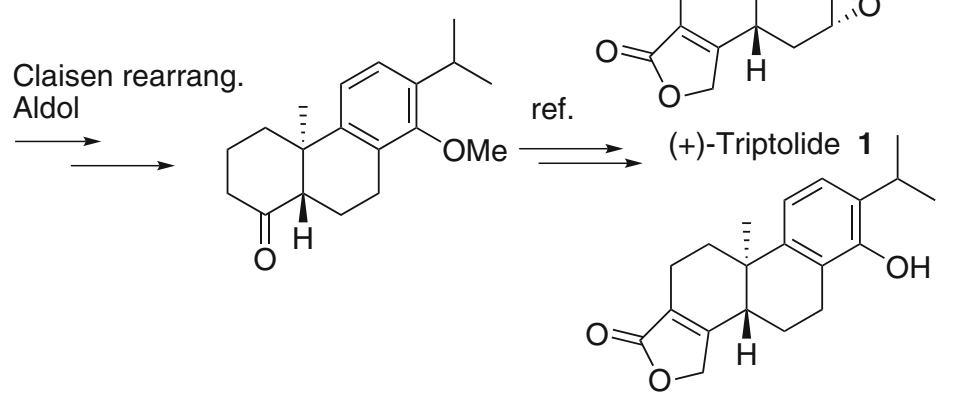

(-)-Triptophenolide 2

Keywords Total synthesis - Catalytic asymmetric - Triptophenolide - Triptolide

Wen-Dan $\mathrm{Xu}$ and Liang-Qun Li have contributed equally to this work.

Electronic supplementary material The online version of this article (doi:10.1007/s13659-016-0100-z) contains supplementary material, which is available to authorized users.

W.-D. Xu · L.-Q. Li · H.-C. Geng · H.-B. Qin ( $₫)$

State Key Laboratory of Photochemistry and Plant Resources in

West China, Kunming Institute of Botany, Chinese Academy of

Sciences, Kunming 650201, Yunnan, People's Republic of

China

e-mail: qinhongbo@mail.kib.ac.cn
W.-D. Xu · L.-Q. Li $\cdot$ H.-C. Geng

University of Chinese Academy of Sciences, Beijing 100049,

People's Republic of China

M.-M. Li

Yunnan Baiyao Group Corporation Limited, Kunming 650032, People's Republic of China 


\section{Introduction}

Tripterygium wilfordii Hook $\mathrm{F}$ has long been used to treat rheumatoid arthritis in southern China. The active component was first determined to be Triptolide (TP) (Fig. 1) after it was isolated by Kupchan in 1972 [1]. The unique tri-epoxide moiety attracted numerous attention to identify its molecular mechanism of action in cancer [2-8], immunosuppression [9-11] and contraception [12]. Triptophenolide, a precursor of TP, exhibited potent anti inflammatory and immunosuppressive activity [13, 14].

By using TP as tool molecule, biological researches have accumulated a lot of discoveries which keep TP as a hot topic. These findings have, in return, promoted the development of efficient synthesis strategy. We seek to discover new lead compounds, especially from nature terpenoids, for the development of anticancer drug [15-17]. Hence, TP is a valuable target for us to investigate SAR of tri-epoxide. We initiated this research in order to develop a catalytic asymmetric synthetic route because it has not been achieved.

Reports of its total synthesis were available from 1980, $[18,19]$ and the maximum productivity was reached around 2000 [20-23]. So far, only two stereoselective synthesis were reported, and both used chiral auxiliaries $[22,24]$. On the other hand, in 2008, Sherburn reported an elegant synthesis with a Diels-Alder reaction [25]. Only preliminary enantioselective synthesis of vinyl iodide was performed and we regard it as a racemic synthesis and will report the first catalytic asymmetric formal total synthesis of (-)-Triptophenolide and (+)-TP, which features a palladium catalyzed conjugate addition of arylboronic acid to cyclic enone to construct all-carbon quaternary stereocenter, followed by new cyclization strategy involving claisen rearrangement [26] and aldol reaction.

The retrosynthetic analysis is depicted in Scheme 1. Unlike precedent methods including biogenetic cascade radical [21, 27] or cationic [28-30] cyclization and alkylation of benzocyclohexanone derivatives, [18, 24] or Diels-Alder reaction [25] to construct the quaternary center, we envisioned that it could be formed enantioselectively via arylboronic acid addition to cyclic enone, a

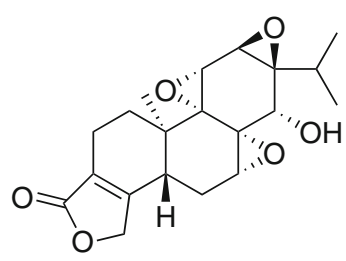

(+)-Triptolide 1

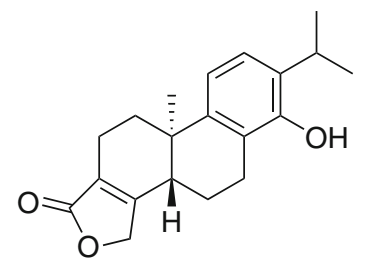

(-)-Triptophenolide 2
Fig. 1 Structures of compounds 1-2

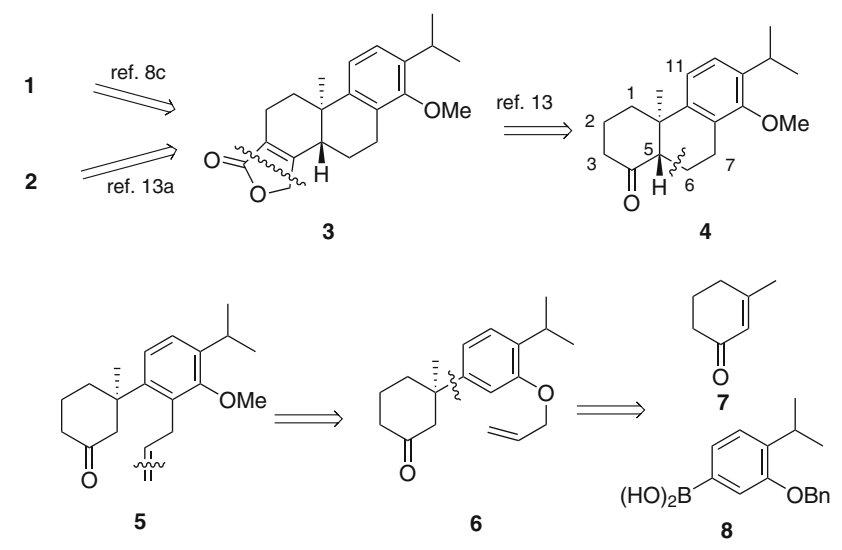

Scheme 1 Retrosynthetic analysis of $\mathbf{1}$ and $\mathbf{2}$

methodology pioneered by Prof. Lu [31] and developed by Prof. Stoltz [32-34].

As illustrated in scheme 1, TP and triptophenolide could be synthesized from tetracycle 3, [28] the butenolide installation could be accomplished from key intermediate tricyclic ketone $4,{ }^{1}$ [35-38] which is accessible by a 3-step transformation including Claisen rearrangement, alkene oxidation and aldol cyclization. Trans-cyclization could be realized if dehydration occurs at C6-C7 after diasteroselective aldol reaction. The quaternary stereocenter in 6 could be constructed by above mentioned coupling reaction.

\section{Results and Discussion}

Our synthesis commenced with coupling reaction of arylboronic acid 8 [15]. Commercially available 3-Me-cyclohexenone was treated with trifluoroacetic palladium and $(s)$ - $t$-BuPyOX ligand in heterogeneous solvent and 9 was isolated in moderate $e e$ and $73 \%$ yield [32]. The absolute configuration was determined accordingly [32]. Removal of Benzyl group by hydrogenation and allylation with allyl bromide afforded $\mathbf{6}$ as precursor of Claisen rearrangement. Treatment of 6 under microwave irradiation for $40 \mathrm{~min}$ gave rise to anticipated allyl phenol $\mathbf{1 1}$ as a minor product, together with tricyclic phenol $\mathbf{1 3}$ which was a product of Conia-ene reaction starting from 11 (Scheme 2). Unfortunately, attempts were failed to improve the yield of $\mathbf{1 1}$ by controlling reaction time and temperature. Alternative strategy need to be adopted to avoid side reactions.

As illustrated in Scheme 2, tautomerization of ketone into enol was the reason of side reaction. Consequently, prevention of the tautomerization by reduction of ketone with $\mathrm{NaBH}_{4}$ could be a choice. In fact, under the same

\footnotetext{
${ }^{1}$ See representative references for catalytic asymmetric construction of 6,6,6-tricycles.
} 


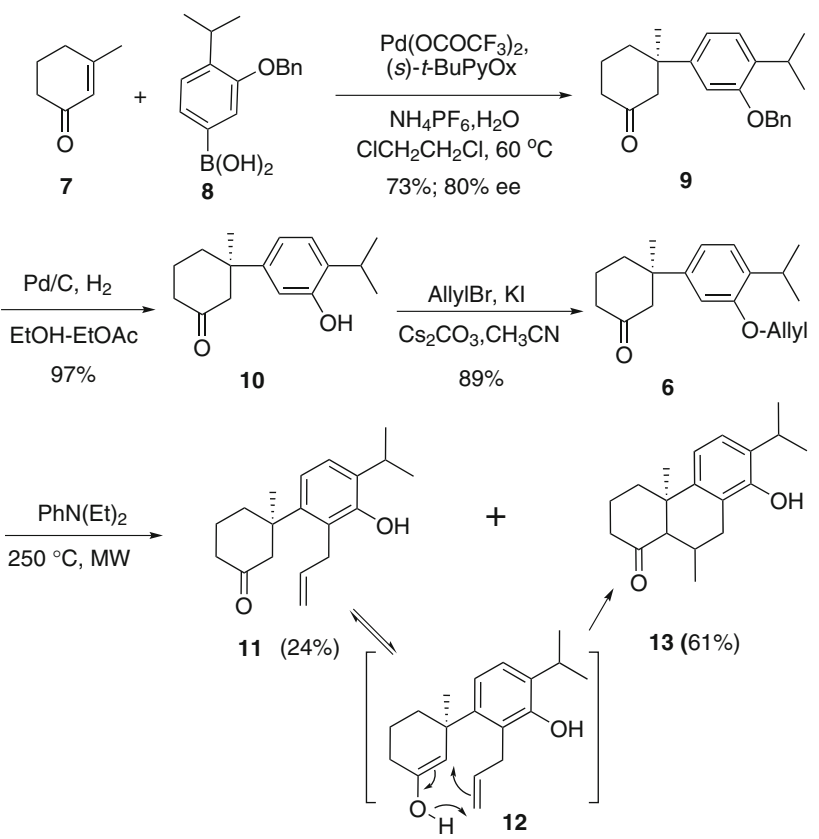

Scheme 2 Construction of quaternary stereocenter and overreacted rearrangement

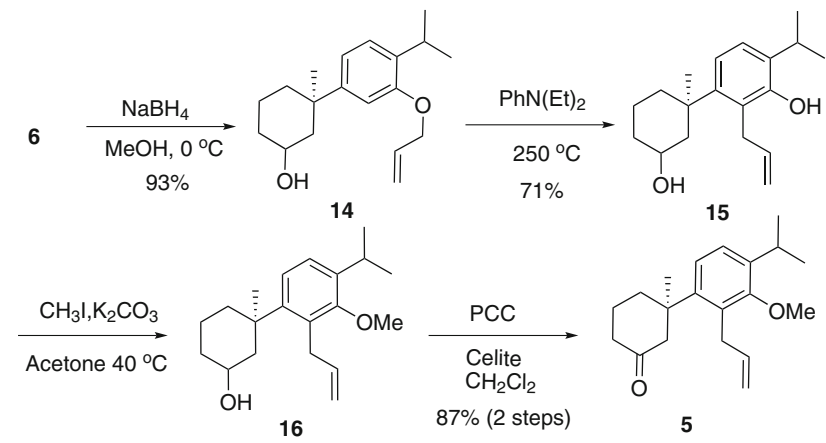

Scheme 3 Successful claisen rearrangement

thermo condition, ortho-claisen rearrangement of $\mathbf{1 4}$ afforded diol 15 in $71 \%$ yield (Scheme 3). Routine methyl protection of phenol and subsequent PCC oxidation produced ketone 5 in $87 \%$ yield in 2 steps.

$\mathrm{RuCl}_{3}$ oxidation of terminal alkene $\mathbf{5}$ to corresponding aldehyde $\mathbf{1 7}$ (75\% yield) set up the stage for diastereoselective aldol reaction (Scheme 4). Both isomers were isolated and trans-isomer was determined by NMR spectrum analysis. We were delightful that dehydration (C6-C7) proceeded in situ to give a thermodynamically stable aromatic alkene $\mathbf{1 9}$ in $51 \%$ isolated yield (dehydration at C5C6 was also possible, however, we did not detect such intermediate by TLC monitor at $\mathrm{rt}$ or higher temperature). TLC analysis showed that cis-isomer $\mathbf{1 8}$ diminished when reaction temperature was elevated. Hence, acceptable yield was obtained by adding $p$-TsOH at higher temperature.

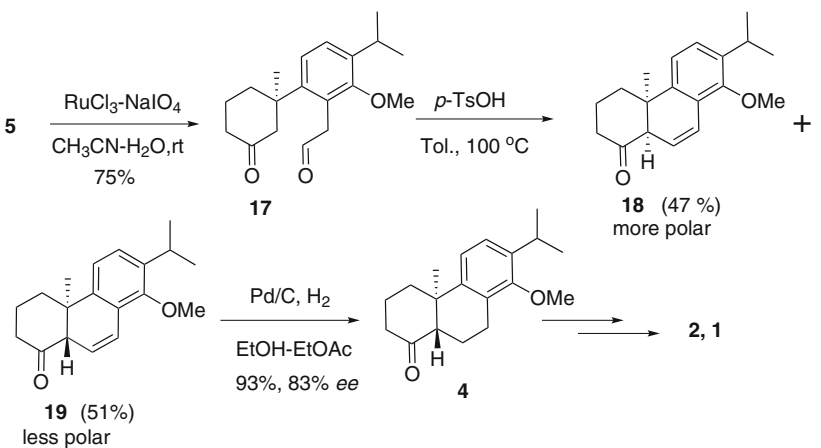

Scheme 4 Aldol cyclization

This provides a method to build cis backbone of 6-6-6 structure which is difficult to access by acidic cyclization [39]. However, after screening of different acids (Camphorsulfonic acid, $\mathrm{TiCl}_{4}, \mathrm{BF}_{3} \cdot \mathrm{OEt}_{2}$, Proline) and bases $\left(\mathrm{KOH}, \mathrm{K}_{2} \mathrm{CO}_{3}\right.$, KO- $t$-Bu), no further improvement was realized to produce more trans isomer. Hydrogenation of 19 furnished key intermediate 4 in $93 \%$ yield and the ee value of $\mathbf{4}$ was determined to be $83 \%$. The spectra of 4 were identical with reported data [28-30]. From 4, (+)-TP and (-)-Triptophenolide could be synthesized with reported methods [28].

In summary, the first catalytic asymmetric formal total synthesis of (+)-Triptolide and (-)-Triptophenolide have been accomplished in 10 steps with $13 \%$ yield. Key reactions involve a catalytic asymmetric construction of quaternary stereocenter and subsequent ring close via Claisen rearrangement, aldol reaction. This work demonstrated a new strategy for asymmetric construction of tricyclic ketone like 4. Further researches on this application in total synthesis of bioactive natural products are ongoing in our lab.

Acknowledgments This work was financially supported by the foundations from NSFC (21372229), High End Talent Program of Yunnan Province (2015HA028), the Applied Basic Research Plan of Yunnan Province Science and Technology Department (No. 2013FB064).

Author contribution The manuscript was written through contributions of all authors.

\section{Compliance with ethical standards}

Conflict of interest The authors declare no competing financial interest.

Open Access This article is distributed under the terms of the Creative Commons Attribution 4.0 International License (http:// creativecommons.org/licenses/by/4.0/), which permits unrestricted use, distribution, and reproduction in any medium, provided you give appropriate credit to the original author(s) and the source, provide a link to the Creative Commons license, and indicate if changes were made. 


\section{References}

1. S.M. Kupchan, W.A. Court, R.G. Dailey, C.J. Gilmore, R.F. Bryan, J. Am. Chem. Soc. 94, 7194-7195 (1972)

2. Y.Y. Zhong, H.P. Chen, B.Z. Tan, H.H. Yu, X.S. Huang, Oncol. Lett. 6, 1084-1092 (2013)

3. J.J. Li, R.L. Liu, Y. Yang, Y. Huang, X. Li, R.M. Liu, X.Y. Shen, Oncol. Rep. 31, 2181-2186 (2014)

4. C.Z. Li, G.Z. Xing, K. Maeda, C.Y. Wu, L.K. Gong, Y. Sugiyama, X.M. Qi, J. Ren, G.J. Wang, Toxicol. Res.-UK 4, 1260-1268 (2015)

5. S. Patil, L.G. Lis, R.J. Schumacher, B.J. Norris, M.L. Morgan, R.A.D. Cuellar, B.R. Blazar, R. Suryanarayanan, V.J. Gurvich, G.I. Georg, J. Med. Chem. 58, 9334-9344 (2015)

6. N. Sharma, M.K. Singh, V. Dudeja, S. Banerjee, A.K. Saluja, Pancreas 44, 1415 (2015)

7. C. Wang, Y. Shan, J.L. Yang, X.L. Xu, B. Zhuang, Y.F. Fan, W. $\mathrm{Xu}$, J. Biomed. Nanotechnol. 11, 805-815 (2015)

8. F. Zhao, W.W. Huang, Z. Zhang, L. Mao, Y.Y. Han, J. Yan, M. Lei, Oncotarget 7, 5366-5382 (2016)

9. S.X. Yang, H.L. Gao, S.S. Xie, W.R. Zhang, Z.Z. Long, Int. J. Immunopharmacol. 14, 963-969 (1992)

10. L.Y. Xu, H.B. Chen, H.B. Xu, X.L. Yang, Eur. J. Pharm. Biopharm. 70, 741-748 (2008)

11. F. Liu, X.S. Luo, S.H. Lan, X.R. Zhang, S.B. Wang, J. Yang, L.S. Levin, Plast. Reconstr. Surg. 131, 343e-350e (2013)

12. A.P. Hikim, Y.H. Lue, C. Wang, V. Reutrakul, R. Sangsuwan, R.S. Swerdloff, J. Androl. 21, 431-437 (2000)

13. X.L. Tao, J.J. Cai, P.E. Lipsky, J. Pharmacol. Exp. Ther. 272, 1305-1312 (1995)

14. R. Li, A.H. Peng, C.M. He, X.H. Wang, J.Y. Shi, L.J. Chen, Y.Q. Wei, Int. J. Mass Spectrom. 278, 38-49 (2008)

15. C.M. Li, H.C. Geng, M.M. Li, G. Xu, T.J. Ling, H.B. Qin, Nat. Prod. Bioprospect. 3, 117-120 (2013)

16. L.Q. Li, M.M. Li, K. Wang, H.B. Qin, Tetrahedron Lett. 54, 6029-6031 (2013)

17. L.Q. Li, M.M. Li, D. Chen, H.M. Liu, H.C. Geng, J. Lin, H.B. Qin, Tetrahedron Lett. 55, 5960-5962 (2014)

18. R.S. Buckanin, S.J. Chen, D.M. Frieze, F.T. Sher, G.A. Berchtold, J. Am. Chem. Soc. 102, 1200-1201 (1980)
19. E.E. Vantamelen, J.P. Demers, E.G. Taylor, K. Koller, J. Am. Chem. Soc. 102, 5424-5425 (1980)

20. D. Yang, X.Y. Ye, H. Xu, K.W. Pang, N. Zou, R.M. Letcher, J. Org. Chem. 63, 6446-6447 (1998)

21. D. Yang, X.Y. Ye, S. Gu, M. Xu, J. Am. Chem. Soc. 121, 5579-5580 (1999)

22. D. Yang, X.Y. Ye, M. Xu, J. Org. Chem. 65, 2208-2217 (2000)

23. D. Yang, X.Y. Ye, M. Xu, K.W. Pang, K.K. Cheung, J. Am. Chem. Soc. 122, 1658-1663 (2000)

24. H.R. Zhang, H.F. Li, J.J. Xue, R. Chen, Y. Li, Y. Tang, C.X. Li, Org. Biomol. Chem. 12, 732-736 (2014)

25. N.A. Miller, A.C. Willis, M.S. Sherburn, Chem. Commun. 1226-1228 (2008)

26. A.M.M. Castro, Chem. Rev. 104, 2939-3002 (2004)

27. E.E. Vantamelen, T.M. Leiden, J. Am. Chem. Soc. 104, 1785-1786 (1982)

28. S. Goncalves, P. Hellier, M. Nicolas, A. Wagner, R. Baati, Chem. Commun. 46, 5778-5780 (2010)

29. B. Zhou, X.M. Li, H.J. Feng, Y.C. Li, Tetrahedron 66, 5396-5401 (2010)

30. S. Goncalves, S. Santoro, M. Nicolas, A. Wagner, P. Maillos, F. Himo, R. Baati, J. Org. Chem. 76, 3274-3285 (2011)

31. S.H. Lin, X.Y. Lu, Org. Lett. 12, 2536-2539 (2010)

32. K. Kikushima, J.C. Holder, M. Gatti, B.M. Stoltz, J. Am. Chem. Soc. 133, 6902-6905 (2011)

33. J.C. Holder, A.N. Marziale, M. Gatti, B. Mao, B.M. Stoltz, Chem. Eur. J. 19, 74-77 (2013)

34. J.C. Holder, L.F. Zou, A.N. Marziale, P. Liu, Y. Lan, M. Gatti, K. Kikushima, K.N. Houk, B.M. Stoltz, J. Am. Chem. Soc. 135, 14996-15007 (2013)

35. S.G. Sethofer, T. Mayer, F.D. Toste, J. Am. Chem. Soc. 132, 8276-8277 (2010)

36. M.A. Schafroth, D. Sarlah, S. Krautwald, E.M. Carreira, J. Am. Chem. Soc. 134, 20276-20278 (2012)

37. K. Surendra, E.J. Corey, J. Am. Chem. Soc. 134, 11992-11994 (2012)

38. J. Deng, S.P. Zhou, W.H. Zhang, J. Li, R.F. Li, A. Li, J. Am. Chem. Soc. 136, 8185-8188 (2014)

39. J. Deng, R.F. Li, Y.J. Luo, J. Li, S.P. Zhou, Y.J. Li, J.Y. Hu, A. Li, Org. Lett. 15, 2022-2025 (2013) 